\title{
Radu Cenușă: „Pădurea va avea foarte mult de suferit, pentru că trebuie gestionată unitar, cu mână forte, ceea ce nu-i stă în fire românului mioritic". Din păcate, profețiile pesimiste ale profeso- rului Prodan s-au adeverit.
}

\section{Laurențiu Giornei}

„Un om care a făcut ceva în viață!’”. Astfel 1-a descris o prietenă comună pe distinsul profesor Radu Cenușă, rugată fiind să povestească istorioare prin care să pot înțelege complexitatea personajului pe care astăzi îl intervievăm. Pe bucovineanul Radu Leontie Cenuşă, apologet al ceea ce am putea numi silvicultura profundă, 1-am cunoscut ocazional, iar realizarea unui interviu cu dumnealui rămâne o bucurie a sufletului.

„Un om care a făcut ceva în viață” este expresia care surprinde, nu doar pentru mine, tăria unui caracter aparte, a unui slujitor al științei forestiere care a reușit să-și facă loc în galeria marilor maeștrii ai silviculturii românești prin inteligență, perseverență, bunătate și corectitudine. Cei care 1-au evocat, la rugămintea mea, au adus în discuție, fără echivoc și aproape la unison, faptul că profesorul Radu Leontie Cenușă este un om de cultură, cu mult bun-simt și înclinat spre poezia naturii. Un brevet de invenție (acordat de statul român acum mai bine de trei decenii) punctează la capitolul atitudinii estetice fundamentale, ca piatră de temelie în cariera sa: „Adaptarea testului Pfeiffer (cromatografie specifică) la regenerarea pădurii”.

A venit pe lume într-o zi specială, pe 21 iunie, cea mai lungă zi anului. Nu putea fi decât o fire solară, luminoasă, plină de entuziasm și Mențiune: acest interviu a fost realizat în prima decadă a lunii aprilie, vreme în care România, dar în special Suceava, suferea din cauza pandemiei generate de COVID-19.

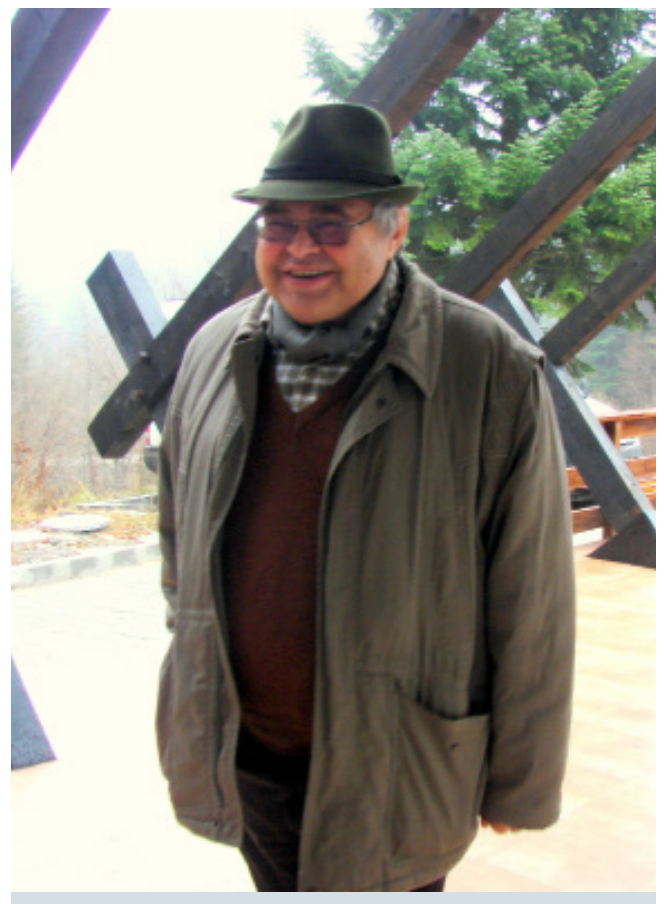

cu o neostoită dorință de a învinge. Chiar dacă nu fățiș, profesorul Radu Cenuşă își recunoaşte latura reflexivă, uneori sceptică, și împăcarea cu ideea neantului (mai cu seamă în ultima vreme), sâcâit fiind de una dintre cele mai parșive afecțiuni: diabetul, cu consecințele sale (face de doi ani dializă şi în februarie a pierdut piciorul drept). Dar asta nu 1-a împiedicat să răspundă franc, natural și cu multă bună cuviință la întrebările acestui interviu. 
Radu Leontie Cenușă s-a născut pe 21 iunie 1951 în localitatea Vatra Moldoviței, județul Suceava, județul cu cea mai mare întindere de pădure din România. Viața profesorului universitar este legată fundamental de pădure. A urmat cursurile Liceului Silvic de la Câmpulung Moldovenesc (1966-1971), iar, între 1971 și 1976, Facultatea de Silvicultură și Exploatări Forestiere a Universității "Transilvania" din Braşov. Este doctor în ecologie forestieră, titlu obținut la Academia de Științe Agricole şi Silvice, cu teza „Cercetări asupra structurii, volumului ecosistemic și succesiunii ecosistemelor forestiere de limită din Carpații nordici (Călimani și Giumalău)". Este profesor universitar, conducător de doctorat, (16 doctori și 3 doctoranzi) expert în proiecte europene.

De asemenea, Radu Cenuşă este/a fost:

- Membru în Comisia Monumentelor Naturii de pe lângă Academia Româna din anul 1998;

- Membru în European Mountain research Initiative(MRI) Network, 2005;

- Membru în Consiliul Științific al ICAS: 1991 - 1998;

- Responsabil al programului național de cercetare „Sisteme silviculturale pentru îngrijirea și regenerarea arboretelor”: 1991 - 1993;

- Membru în comisia de specialitate „6.2. Silvicultura" al Colegiului Consultativ pentru Cercetare Aplicativă și Dezvoltare 1994 -1997;

- Președinte al Consiliului Științific al Parcului Național Călimani 2004 - 2009; membru din 2009 până în prezent;

- Şeful Staţiunii ICAS Câmpulung Moldovenesc, 1990 - 2004;

- Decan al Facultății de Silvicultură, Universitatea „Ștefan cel Mare”, 2004 - 2008;

- Redactor-șef al revistei „Bucovina Forestieră”;

- Membru în Consiliul Științific al revistei „Annals of Forest Research";

- Cetățean de onoare al localităţilor Vatra Moldoviței, 2009, și Vama, 2012.

Premii și distincții:

- Premiul "Leopold Pfeil" al Fundației Freiherr von Stein, Hamburg, 1984;

- Premiul "Traian Săvulescu" al Academiei Române, 1990;

- Premiul "Progresul Silvic", 1992.

62
1. Domnule profesor, vă mulțumesc că ați binevoit să acordați acest interviu și am să încep prin a vă ruga să dezvăluiți cititorilor care a fost resortul care a stat la baza inițierii dumneavoastră în tainele silviculturii. Şi eu vă mulțumesc că mă supuneți tirului întrebărilor, răspunsul este simplu: întâmplarea. În anul 1966, în România au fost reînființate liceele industriale. În Câmpulungul Bucovinei, în inima spațiului silvestru, avându-se în vedere și tradițiile în formarea lucrătorilor pădurii (Școala de arte și meserii, Institutul, Grupul școlar silvic) a luat naștere Liceul Industrial Forestier. Asta a fost prima componentă (apropiere de casă, teama schimbării mediului natal). A doua a fost determinarea (nu a mea) indusă de bunicul patern și de tatăl meu care au avut strânse legături cu pădurea, legături profesionale și de pasiune (ambii fiind vânători cunoscuți pe Valea Moldoviței). Așa am ajuns să susțin examen de admitere la această școală în iunie, 1966.

2. V-ați născut în Vatra Moldoviței, în vatra unui mirific sat turistic aflat în grija UNESCO. Mai mult, acum 488 de ani Petru Rares punea piatra de temelie a renumitei Mănăstiri Moldovița - simbol de artă și cultură medievală, ocrotită de dinastia voievozilor Mușatini. Neobișnuit poate pentru mulți, pe pereții mănăstirii sunt pictați, alături de sfinți, Platon, Aristotel, Sofocle și Pitagora, aceștia fiind considerați deschizători de drumuri ai creștinismului. V-a inspirat (și) acest fapt? $\mathrm{Nu}$ pot spune că statutul de locuitor al vetrei Mănăstirii Moldovița $\mathrm{m}$-a inspirat în alegerea profesiei. M-a inspirat mai ales în atitudini, comportamente, de-a lungul întregii vieți. Pentru mine (ca și pentru majoritatea concetățenilor mei), Mănăstirea s-a aflat la originea a trei axe (geometric vorbind): credință, educaţie, muncă. Aceste lucruri le-au avut înaintaşii mei şi aceleaşi lucruri simt că le-am primit și eu.

3. În septembrie se vor împlini 54 de ani de când ați luat calea Câmpulungului pentru a deveni licean. Și nu unul oarecare, ci unul silvic. Dacă nu ar fi fost acel liceu, acea chemare, ce ați fi ales în schimb, ca viitoare profesie?

Vedeți Domnia-Voastră, că spre Liceul Silvic nu am fost atras de vreo chemare ci mai mult împins de la spate. Dacă era să dau glas pasiunilor mele, 
m-aş fi îndreptat spre o profesiune din domeniul mecanicii (în şcoala generală voiam să mă fac tractorist). Și acum îmi place să meșteresc.

\section{Până la urmă, destinul dumneavoastră s-a împletit binevoitor cu silvicultura. Spuneți-ne, vă rog, dacă în tot acest timp v-a impresionat cineva, dacă ați avut vreun model pe urmele căruia să vreți să călcați și să continuați drumul.}

Bine ați spus ,până la urmă”. Eu eram obișnuit de foarte mic cu pădurea (se afla la 70 de metri de casa natală, numai peste râul Moldovița). Poate de aceea nu-i acordam atenție deosebită. (Deși una din primele amintiri este legată de pădure când, pe la 4 ani, mergând cu o mătușă la cules ciuperci, m-am simțit ca într-o biserică foarte mare și foarte întunecoasă). La sfârșitul anului I, în iunie 1967, am fost în prima mea practică cu toți colegii la Ocolul Silvic Dorohoi, în pădurea Cordăreni, unde am luat contact cu pădurea de foioase (alt gen de pădure, mai luminoasă, mai primitoare) și unde, directorul liceului, care conducea practica, mi-a cerut să intru la doi metri în profilul de sol și să-l descriu (asta fiind primul contact cu bucuriile pe care le poate da cercetarea). După câteva ore am perceput că atitudinea mea era pe cale să se schimbe, că încep să mă apropii din ce în ce mai mult de pădure. Această apropiere s-a făcut tot mai mare, schimbându-se în pasiune (era să spun cuvântul magic: dragoste). Acum, după trecerea unor ani buni, pădurea mi-a devenit o necesitate vitală. (Din păcate încă trebuie să o admir de la fereastră). Dar rog să-mi fie iertată divagația și să revin la model. Pentru mine este dificil să aleg un model, pentru că din fericire am avut parte de multe personalități care au avut o influență importantă asupra mea. Se constituie o matrice din oameni în epoci diferite cu o rezultantă totală: viaţa unui om. Pentru mine această matrice a fost practic construită ca de altfel pentru fiecare ,trestie gânditoare” din bunici, părinți, învățători, profesori, colegi, prieteni, soție. Dacă este vorba de formarea/devenirea mea ca cercetător, nu pot să nu invoc două nume: directorul liceului, profesor doctor Petre Ciobanu, care prin răbdare, pasiune și știință, $\mathrm{m}$-a dirijat spre cercetare (atât la cursuri, cât și la Cercul Tehnic de Silvicultură) și doctorul inginer Radu Ichim pe care l-am numit profesorul meu post universitar și post doctoral, care deși având fire și educație ,, teutonică” mi-a fost, cât a trăit, foarte apropiat. Ambii au fost profesori la Institutul de Silvicultură.

\section{Descrieți, vă rog, cum era silvicultura românească} în anii când dumneavoastră ați început să profesați.

$\mathrm{Nu}$ vă pot da date exacte despre silvicultura românească, în schimb, am avut ocazia să cunosc oameni care erau cu sufletul și mintea pentru silvicultura Bucovinei.

Aceasta pentru că în acest spațiu, chiar după 15 ani, inerția (sens pozitiv) profesionalismului de la Fondul Bisericesc era încă sesizabilă (amenajarea pădurilor după principiile și normele de la serviciul de amenajare al Fondului, personal bine educat, conducători integri). La baza selecției și promovării întregului personal era aşezată competența profesională. Activitățile din silvicultură erau sprijinite de politicile naționale care, toate vizau dezvoltarea și conservarea pădurii. Atenția era canalizată spre lucrările de împăduriri, de protecție, de îngrijire, de aplicarea tratamentelor și mai puțin spre pază sau exploatare sau comerț. Aș vrea să invoc aici o scrisoare adresată în 1992, de către profesorul Michail Prodan către domnul doctor Radu Ichim, în care arăta că se bucură de libertățile aduse poporului român de anul 1989, dar crede că pădurea va avea foarte mult de suferit, pentru că trebuie gestionată unitar, cu mână forte, ceea ce nu-i stă în fire românului mioritic. $\mathrm{Cu}$ regret trebuie să recunoaștem, după 30 de ani, că această profeție pesimistă s-a adeverit.

\section{Acum, vă rog, să definiți silvicultura românească din prezent. Descrierea să fie făcută în doar cinci cu- vinte.}

Silvicultura, în general (mă refer la silvicultură ca activitate umană, nu ca disciplină științifică), are două componente importante: pădurea și oamenii care o gestionează, așa că trebuie să spun cate 5 cuvinte pentru fiecare?

Atunci pentru pădure pot spune: salvatoare, leac, necesară, frumoasă, neînțeleasă.

Pentru oameni (cu excepții) în raport strict cu 
pădurea: avizi, superficiali, dezinteresați, ruralizați, educabili.

7. Ca renumit cercetător, care a fost proiectul de care v-ați atașat cel mai mult? Poate fi acesta continuat? Dacă da, atunci de către cine și cum?

În toată munca mea de cercetător (nu cred că prea renumit) am lucrat la multe proiecte, dar în două am pus energie cu adjuvantul suflet: ecologia pădurilor de la limita superioară a vegetaţiei și structura și funcționalitatea pădurilor naturale. Toate temele științifice fără excepție sunt supuse complementarității, aceasta este o lege a progresului și un atribut al ființei umane. În toate domeniile, progresul se face prin schimbare de paradigmă, datorită avalanșei bibliografice, dezvoltării informaticii, dezvoltării echipamentelor de investigare, cuplate cu cerințele societății (dacă și le poate exprima). Așa că și în cazul proiectelor la care am lucrat sunt de adus încă multe informații, (vorba profesorului meu dr. ing. Radu Ichim „dați-mi un capăt de funie de nisip"). În prezent, pădurea naturală prezentând un interes din ce în ce mai amplu, sunt mai multe echipe care și-au îndreptat privirile către ea, inclusiv la facultatea noastră. Șeful de lucrări Cătălin Roibu construiește, împreună cu cercetători din străinătate, o echipă de viitor, dar sunt și alte echipe la INCDS „Marin Drăcea”, la Univesitatea „Transilvania” din Brașov, poate și altele pe cale de afirmare. Extinderea cercetărilor pe o anumită tematică depinde de interesul finanţatorului, dar și de pasiunea cercetătorului. Așa că uşile rămân deschise. (Doar pe jumătate?)

8. Dați, dacă doriți, câteva exemple de tineri cercetători silvici care ar putea schimba fața actuală a domeniului forestier românesc.

Ați spus „dacă doresc” așa că voi răspunde după cum cred eu de cuviință: nu am agreat niciodată clasificarea cercetătorilor după anumiţi indici scientometrici întrucât potențialul creativ nu poate fi cântărit. Unii au punctaj mare în clasamente și nu au făcut decât să se semneze coautori pe un articol sau pe o carte. Dar sunt şi oameni care pur şi simplu lucrează la o temă ani de zile, fără prea multe publicații. 64
Este adevărat că revoluția informatică este doar informatică, fără să pătrundă în creierul și în sufletul uman. În cercetarea silvică și în învățământul superior silvic sunt angrenate forțe cu un potențial deosebit pe tot cuprinsul României. Lucrează în prezent și vor lucra și în viitor, fie în echipe, fie individual, în cadrul pregătirii tezelor de doctorat. Așa că, vă rog, nu-mi cereți nume.....

9. Care ar fi domeniul științific în care românii ar putea avea un cuvânt mai bun de spus? A fost, de exemplu, Michail Prodan, tot un bucovinean, care este considerat "părintele biometriei moderne". De atunci, lucrurile însă s-au schimbat, ne-au luat-o alții înainte. Avem vreun as în mânecă să revenim în topurile cercetării silvice internaționale?

Vă răspund că domeniul de cercetare al pădurilor naturale şi seminaturale ar reprezenta o perspectivă pentru cercetarea silvică românească. Dar dacă nu trecem rapid la muncă vor veni străinii care sunt interesaţi în mod direct de acest aspect, iar noi vom fi numai furnizorii materiei prime, la fel ca în cazul coproducțiilor cinematografice ,ei cu actorii, noi cu caii”, la fel ca în majoritatea ramurilor economice. Problema devine din ce mai serioasă, dar din păcate nu depinde de sistemul de cercetare științifică, ci de decidenții politici ai cercetării. Mâneca noastră nu mai are nici un as, poate doar ceva "valeți". Săraci, cum suntem, când este vorba de cercetarea științifică nu avem cum să pătrundem în topul cercetării științifice internaționale. Ați fost la vreo manifestare internațională să vedeți cu ce ochi sunt priviți românii? (la întoarcere, declarațiile de presă fac floricele întotdeauna, dar eu am simţit pe propria piele respectul disimulat al unor colegi străini, este adevărat, nu toți). Pentru a pătrunde în marea știință silvică trebuie făcute investiții substanţiale în echipamente performante (nu se mai poate merge în pădure cu clupa, dendrometrul și carnetul de teren) în programe informatice de vârf, în mobilități, în posibilități de documentare. Trebuie finanţate proiecte ample, pe durate mari, pe spații extinse. Ori la noi, ciclurile de cercetare rareori ajung la 5 ani, iar controlul asupra rezultatelor cercetărilor se face 
încă de către contabili. Nu fac nici o afirmație răutăcioasă, dar în mod real birocrația noastră excesivă frânează dezvoltarea cercetării $(\mathrm{Nu}$ o spun numai eu).

10. De numele dumneavoastră se leagă două dintre momentele remarcabile pentru silvicultura românească: înființarea Facultății de Silvicultură din cadrul Universității "Ștefan cel Mare" din Suceava și reapariția, după fix 0 jumătate de veac, a revistei "Bucovina Forestieră". Povestiți-ne, vă rog, câteva amănunte despre aceste importante evenimente!

Ar fi mult ce povestit, dar încerc să fiu cât mai scurt. Din start vă spun că am fost un simplu pion în cele două partide de șah care s-au jucat în județul Suceava, grație evenimentelor de la sfârșitul anului 1989. În decembrie 1989, în guvernul Roman a fost numit titular la Ministerul Apelor, Pădurilor și Mediului înconjurător, profesorul Simion Hâncu. Acesta, dorind să facă o echipă solidă, competentă, când a primit spre aprobare dosarul domnului dr. ing. Nicolae Geambaşu (care câștigase concursul pentru postul de director științific la ICAS, din postura de șef al Stațiunii de cultura molidului de la Câmpulung), l-a numit imediat, fără niciun aviz, secretar de stat la păduri. Imediat după numire, în primul sfârșit de săptămână, când noul demnitar a venit la familia care încă locuia aici, duminica, la ora trei am fost convocați (Nicolae Geambașu, Ion Barbu și subsemnatul) de către domnul Ichim care ,cu cuțitele pe masă” a lansat ideea reînființării Facultății de Silvicultură la Câmpulung. Pentru că universitatea de la Suceava era în curs de transformare din institut de subingineri, domnul Ichim a fost de acord și cu această variantă. Imediat, a doua zi, secretarul de stat Nicolae Geambașu a prezentat și susținut propunerea Ministrului învățământului, filosoful Mihai Șora. Acesta a trimis o comisie formată din specialiști din învățământ și din cercetarea silvică la Suceava. Între timp, rectorul noii universități, academicianul Emanuel Diaconescu, care a agreat ideea, 1-a delegat pe profesorul Gheorghe
Frunză (Facultatea de mecanică, absolvent de școală silvică) la stațiunea de la Câmpulung pentru a întocmi o documentație privind ,necesitatea și oportunitatea" înființării acestei facultăți. Comisia, condusă de către directorul direcției generale a învățământului superior, a fost formată din mai mulți membri din care îmi aduc aminte de profesorul Emanuel Diaconescu, profesorul Darie Parascan, directorul din ministerul Pădurilor, dr. ing. Ioan Milescu, dr. ing. Gheorghe Frunză, dr. ing. Radu Ichim, dr. ing. Ion Barbu și ultimul, ,cu voia dumneavoastră”, dr. ing. Radu Cenuşă. Pentru a fi și mai convingători noi, cei de la Câmpulung, am dus și aparatură de cercetare. Comisia a avizat iniţiativa, iar în primul parlament de după 1989, profesorul doctor Mihai Iacobescu, pe atunci senator, a sprijinit-o din toate puterile. Un ajutor a fost dat și de către directorul Direcției Silvice Suceava, ing. Vasile Panteliuc, care a făcut parte din comisia amintită.

Odată îndeplinite formalitățile, tot la propunerea domnului Nicolae Geambașu și datorită conjuncturii politice, ca decan a fost numit domnul dr. ing. Ioan Milescu care putea să susțină existența facultății prin prestigiul în breasla silvicultorilor din ,cercetare - învăţământ - producție" prin experiența managerială, prin lucrările sale științifice. Domnia sa a înțeles aplicarea acestei propuneri ca pe o mazilire, însă oricum nu mai putea rămâne pe funcția pe care o ocupase până în 1989. (De aici o oarecare răceală, poate chiar aversiune, față de domnul Nicolae Geambașu). Cu toate acestea,

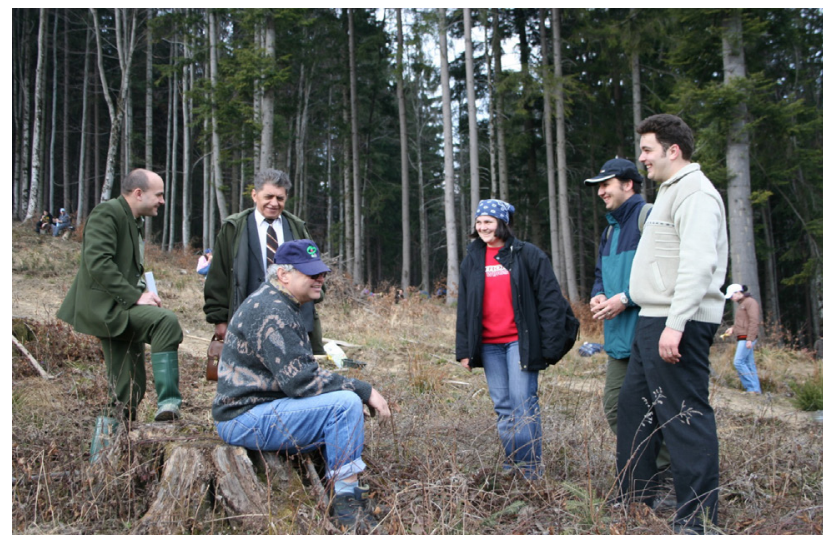


numirea s-a dovedit a fi foarte inspirată pentru că noul decan a adus, de la Brașov, profesori de mare calibru precum prof. dr. ing. Victor Stănescu, prof. dr. ing. Darie Parascan, prof. dr. ing. Rostislav Bereziuc, prof. dr. ing. Ilie Popescu, prof. dr. ing. Nicolae Boș şi, mai târziu, pe doamna prof. dr. ing. Filofteia Negruțiu și a muncit din toate puterile pentru punerea acestei instituții pe o temelie trainică. Toate personalitățile care au adus un mic aport la devenirea de azi a facultății merită mulțumirile mele.

Acum să trecem la a doua parte a întrebării referitoare la reluarea publicării revistei noastre „Bucovina Forestieră”. Iniţiativa a aparţinut tot domnului dr. ing. Radu Ichim care a lansat în 1993 revista prin adrese către potențialii autori, a făcut proiectul primului număr având pe frontispiciu mottoul „Pădurea este templul sfânt al lui Dumnezeu, iar noi suntem preoții ei”, care trebuie să rămână atât timp cât va apărea revista. Dar pentru că am vorbit de două personalități importante, nu pot explica aversiunea domnului Milescu față de domnul Ichim, mai ales că ultimul i-a fost profesor la Institutul de silvicultură de la Câmpulung. După (re)înființarea facultății la Suceava, domnul Ichim a crezut că va fi invitat, ca profesor, pentru că avea experiență didactică (conferențiar la Câmpulung și Braşov) și era unul din vârfurile biometriei românești. Nu a fost să fie......

11. Exemplificați, vă rog, câteva metode și/sau idei prin care sectorul silvic românesc ar putea beneficia de zile cât mai bune.

Silvicultura din România este așa cum este, nu din cauza lipsei ideilor sau metodelor de lucru, ci din pricina sistemului și a gândirii generalizate în societate și în mediul politic ,pădurea crește și așa, nu a pus nimeni apă la rădăcinile copacilor"! Mai ales după 1989, politicienii au descoperit cât de importantă este pădurea ca sursă financiară electorală (și nu numai), iar interesele politicienilor au venit în cascadă asupra pădurii și oamenilor acesteia. Metodele sunt cunoscute (avem destule norme tehnice, cercetări) dar nu sunt aplicate. Deci, zile mai bune pentru silvicultura românească vor veni atunci când vor fi aplicate legile și normativele și când controlul va fi făcut cu seriozitate și cu bune intenții.

12. Care sunt, în opinia dumneavoastră, trei dintre cele mai nocive decizii care au dăunat sau chiar mai afectează silvicultura românească?

Privatizarea haotică a fondului forestier, bulversarea cadrului legislativ privind gestionarea pădurii, incoerența organizatorică.

13. În celebra, mai ales printre forestieri, fabulă "Toporul și pădurea" concluzia arată "că în fiece țarăl cele mai multe rele nu vin de afară,/Nu le aduc străinii, ci ni le face toate/Un pământean de-ai noștri, o rudă sau un frate". Sunteți de acord cu Grigore Alexandrescu? Exemple?

$\mathrm{Da}$, sunt de acord cu fabulistul. Exemple? Numeroase. Dar numai faptul că exportăm lemn semifabricat, fără valoare adăugată, poate fi văzut în toată țara (la vămi, în porturi....).

14. Se pune tot mai des accentul pe schimbarea strategiei forestiere care să trimită lemnul din pădure pe drumuri mai avansate, de exemplu industria textilă sau cea farmaceutică. Considerați că silvicultura românească are posibilitatea de a face ușor și repede această trecere?

Silvicultura, de la nașterea ei produce lemn, din păcate numai pentru asta ia bani. Dar oferă în același timp o mulțime de alte bunuri și servicii (pe care, dacă le voi enumera risc să frizez derizoriul). Deci, pentru silvicultură, principala direcție strategică este extinderea și conservarea pădurii. Industria trebuie să facă strategii de valorificare a lemnului și a tot ce poate oferi aceasta. Pentru că are multe de oferit. Am și eu o întrebare: cam câți români au auzit de silvoterapie?

15. Din punct de vedere al exploatării masei lemnoase suntem, ca țară, destul de în urmă. Mă refer mai ales la mijloacele tehnice și utilajele cu care se exploatează și acum pădurea. Sunteți de acord cu această afirmație?

$\mathrm{Da}$, sunt de acord, dar cred că este un mare avantaj pentru pădure. Cercetările au dovedit că utilajele de exploatare oricât de ușoare, de ecologice, oricât de late ar fi pneurile sau șeni- 
lele, pot produce daune solului forestier (modificarea structurii humusului, compactizare, cu dispariţia hifelor ciupercilor de micoriză, modificarea circuitului apei și a substanțelor nutritive) care se repară în câteva sute de ani. Așa că mai bine lipsă, din punctul meu de vedere. Apropos de utilaje: știți de ce au dispărut funicularele? Pentru că nu puteau să ducă seara câte o sarcină de lemn în sat, aşa cum o fac prea utilizatele tractoare articulate.

\section{Zilele acestea s-a vorbit, poate mai mult ca nicio- dată, de speranță. Care este speranța dumneavoastră pentru viitor?}

Prima din speranțele mele este legată de suprimarea virusului chinezesc, că se vor găsi mijloace „de prevenire și combatere” cum se spune în limbajul silvicultorilor (lumea actuală poate face acest lucru). A doua, se referă la un viitor mai bun pentru pădure pentru că societatea trebuie să învețe despre importanța sa strategică. Și a treia se leagă de sănătatea proprie. Sper să mai pot lucra cu tinerii mei colegi, cu studenții, dacă nu pentru altceva măcar pentru infuzia de tinerețe și...speranță.

Vă mulțumesc!

Abstract. Radu Cenușă: " The forest has been suffering a lot, because it must be managed unitarily, with a strong hand, which is not in the nature of the Mioritic Romanian ". Unfortunately, Prodan's pessimistic prophecies came true.

Radu Leontie Cenușă was born on June 21, 1951 in Vatra Moldoviței, Suceava County. In 1976, he graduated the Faculty of Silviculture and Forestry Exploitation from "Transylvania" University of Brasov. He is doctor in forest ecology, university professor, doctoral supervisor, expert in European projects, member of specialized commissions, Scientific Councils and chief-editor of the journal "Bucovina Forestieră". Throughout his activity, Radu Leontie Cenușă received a series of awards and distinctions.

Well-known hunters of his native lands, father and grandfather were the ones who determined Radu Leontie Cenuşă to discover the secrets of forestry. The proximity to Moldoviţa Monastery inspired him in attitudes and behaviors, throughout his life, being at the origin of three pillars his personality relies on: faith, education and work. The scientific career has been marked by professor doctor Petre Ciobanu and doctor engineer Radu Ichim, both professors at the Institute of Forestry.

"A man who did something in life" captures the stamina of a special character, who has been always a servant of the forest science and managed to make his own way on the gallery of the great masters of Romanian forestry through intelligence, perseverance, kindness and fairness.

At the beginning of his career, the basis of selecting and promoting the staff of Romanian forestry was professional competence. All forest-related activities were supported by consistent national policies, all aimed at developing and conserving the forest. Currently, forestry has two important components: the forest and the people in charge of managing it. The chaotic privatization of the forestland, numerous inconsistencies of legal framework and the organizational incoherence are the three of the most harmful decisions that have damaged or affected Romanian forestry. From the point of view of timber exploitation, as a country we are quite behind. The lack of technical means and modern equipment, the fact that we export semi-finished wood, without added value, can be seen all over the country. Better days for Romanian forestry will come when laws and regulations will be applied and when control will be done seriously and with good intentions.

According to his opinion, in forestry research and in forestry higher education, forces with a special potential are engaged throughout Romania, which could change the current face of the Romanian forestry. In particular, the research field of natural and semi-natural forests would come up with a fresh perspective on Romanian forestry research. However, in order to enter the high-level forestry science, substantial investments must be made in high-performance equipment, state-ofthe-art software, in personnel mobility, and documentation. Or, excessive bureaucracy slows down the development of research.

Nevertheless, his high hopes go to a better future for the forests, based on a realistic public awareness and professionalism. The main strategic direction must be found in forest extension, forest conservation and wood mobilization in order to make the best of what forests offers to society. Simply because the forest has still a lot to offer.

Author. Ciornei Laurențiu (laurentiu.ciornei@ince. ro) - Center for Study and Research for AgroForestry Biodiversity/Romanian Academy, 13, Calea 13 Septembrie, 050711, Bucharest, Romania. 